\title{
The Relationship of Identity Styles and Body Image with Anxiety among High School Students
}

\author{
Meisam Dehvari ${ }^{1}$, Hossein Jenaabadi ${ }^{2} \&$ Abdulwahab Pourghaz $^{2}$ \\ ${ }^{1}$ Educational Research, University of Sistan and Baluchestan, Zahedan, Iran \\ ${ }^{2}$ Faculty Member, University of Sistan and Baluchestan, Zahedan, Iran \\ Corresponding: Hossein Jenaabadi, Faculty of Educational Sciences and Psychology, University of Sistan and \\ Baluchestan, Zahedan, Iran. E-mail: hjenaabadi@ped.usb.ac.ir
}

Received: January 18, 2016

Accepted: February 5, 2016

Online Published: February 29, 2016

doi:10.5539/mas.v10n3p178

URL: http://dx.doi.org/10.5539/mas.v10n3p178

\begin{abstract}
The present study aimed to examine the relationship of identity styles and body image with anxiety among students. This was a descriptive-correlational study. The statistical population included 240 second period male high school students in Saravan. To examine identity styles, body image and anxiety, respectively, Identity Style Questionnaire (IS-6G), the Fisher Body Image Scale (1970), and the Cattell Anxiety Scale Questionnaire were used as data collection tools. The obtained data was analyzed using both descriptive and inferential statistics (Pearson correlation coefficient and regression analysis). The results of the current study revealed that identity styles and body image were significantly and positively related to anxiety. Moreover, among identity styles, informative and commitment styles had no significant relationships with anxiety; however, normative identity style was significantly and negatively correlated with anxiety, such that with an increase in normative identity style, anxiety decreased. Additionally, the results indicated that confused/avoidant identity style was significantly and positively related to anxiety.
\end{abstract}

Keywords: identity styles, body image, anxiety, students

\section{Introduction}

Adolescence is a stage full of physical and emotional changes and transformations regarded as one of the most significant periods of an individual's life in which the individual experiences various difficulties in relation to his/her body image (Cason, Verna, and Benner, 2000; as cited in Amidi et al., 2006). Having an appropriate mental image of one's own body is of great importance since, in adolescence, this image has complicated psychological effects on all other aspects of one's life and is a key factor in determining how he/she communicates with others (Boyd, 2002; as cited in Pahlavanzadeh et al., 2005). Like all other transitional periods, adolescence is accompanied with problems, conflicts, crises and changes. The most significant development in this period is called "puberty". Puberty affects all physical and mental aspects of an adolescent's life including his/her identity and body image (Dehghanzadeh et al., 2011).

An individual's body image plays a key and significant role in his/her presence in the community and people conduct initial assessments based on it. When an individual feels that he/she cannot have a positive effect on the society, he/she may lose his/her confident to have a physical presence in the society. These people probably experience high levels of social physical anxiety. Beker and Gringart (2009) suggested that when women, due to reduced satisfaction with their body image, have less continuous physical presence in the society, they usually experience high social physical anxiety, underestimate themselves and consider others more attractive than themselves in all circumstances. This can be the reason of the fact that why women always focus on immediate weight loss. They, in fact, use it as a method to reduce their social physical anxiety.

Webster and Tiggemann (2003) in a study concluded that the prevalence of body dissatisfaction can be considered as a major concern, since it is associated with other mental disorders including low self-esteem, depression, social anxiety and the like.

Physical appearance and body image are among important factors which form adolescents' identity (Jomeen and Martin, 2005; as cited in Gorousi et al., 2013). Identity is a feeling that is experienced consciously and arises from one's interaction with his/her social reality. 
Identity of a person constantly changes in response to changes in the social environment. According to Erikson, establishment and maintenance of a strong sense of identity is of great importance. He asserted that lack of a strong sense of identity is one of the primary determinants of psychological harm and social incompatibility (Erikson, 1959).

Hosseini Tabatabaee (1998), in a study entitled "The Relationship between Identity Statuses and Coping with Crises in Adolescents and Young Adults", inferred that people with identity diffusion applied more emotion-focused coping styles and people who successfully achieved identity used more problem-focused coping styles. In this study, no significant difference was found among males and females with regard to achieving identity statuses.

Ghazanfari (2003) examined the relationship between identity styles and mental health of adolescents. The obtained results showed that informative and normative identity styles were significantly and positively related to subjects' level of mental health and confused/avoidant identity style was significantly and negatively correlated with the level of mental health.

Dissatisfaction with body image taking place in adolescence along with other important factors including the problems of everyday life (academic, mental, and social problems) all lead to various physical and mental problems such as depression, drug abuse, anxiety and the like (Borzenskowski and Bayer, 2005). Studies conducted to examine body image are limited (Gleeson, 2006) and few studies have been carried out to investigate the effect of body image on anxiety and to examine the role of identity styles in anxiety among students; therefore, conducting such studies seems essential.

In this regard, the present study sought to answer these questions:

1) Are identity styles and body image that adolescents have about themselves significantly related to anxiety?

2) Is there any significant relationship between identity styles and anxiety of second grade male high school students?

3) Is there any significant relationship between body image and anxiety of second grade male high school students?

\section{Methods and Materials}

\subsection{Statistical Population and Sample}

The statistical population of the present study included all second grade male high school students studying in the second period in Saravan ( $\mathrm{N}=671$ ). To select the sample, stratified random sampling method was used. Based on the Morgan table, the sample size was determined 240 students. After referring to each school and considering the number of classes, the final sample was selected randomly $(\mathrm{N}=240)$ and the mentioned questionnaires were distributed among the students.

\subsection{Data Collection Tools}

\subsubsection{Identity Style Questionnaire (IS-6G)}

This questionnaire was initially designed by Berzonsky (1989) to measure cognitive-social processes through applying which adolescents deal with issues related to their identity. This questionnaire evaluates four identity styles including informative, normative, commitment, confused/avoidant. Berzonsky (1997) in the last (third) revised version of the questionnaire reported that the Cronbach's alpha coefficient of this questionnaire $(\mathrm{N}=618)$ for each identity styles including informative, normative, confused/avoidant, and commitment was respectively $0.70,0.64,0.76$, and 0.71 (Ghazzanfari, 2003).

\subsubsection{Body Image Scale}

This scale was developed by Fisher in 1970 and has 46 items. Each item has a value from 1 to 5 (1=very dissatisfied, $2=$ dissatisfied, $3=$ neither dissatisfied nor satisfied, $4=$ satisfy, $5=$ very satisfied). Obtaining the score of 46 indicates some disorders and higher scores (with a maximum of 230) indicate lack of any disorders. In a study, using Cronbach's alpha coefficient, Rahdar (2013) calculated the reliability of dimensions of head and face, upper limbs, lower limbs, the general characteristics of the body, and the whole scale which was respectively $0.87,0.88,0.80,0.90$, and 0.96 ., to examine the reliability, Cronbach's alpha coefficient was used, the result of which for dimensions of head and face, upper limbs, lower limbs, the general characteristics of the body, and the whole scale was respectively $0.88,0.90,0.85,0.89$, and 0.96 (Yazdanjo, 2000).

\subsubsection{The Cattell Anxiety Scale Questionnaire}

This questionnaire includes 40 items. It can be conducted in most cultures for the ages higher than 14 and 15 
years old. Participants' answers can be checked through using an answer sheet and then the total score of the first 20 questions (covert anxiety) and the total score of the second 20 questions (overt anxiety) are separately determined and the sum of these two scores provides a participant's overall score. The validity of this scale was examined through conducting the scale again and again, the results of which were always higher than $70 \%$. With regard to its validity, the following table represents the related data (Ganji, 2001).

Table 1. Results of normal, neurotic and groups with anxiety hysteria

\begin{tabular}{llll}
\hline Group & $\mathrm{N}$ & Mean & SD \\
\hline Normal & 795 & 26.75 & 11.16 \\
Neurotic & 154 & 38.54 & 12.40 \\
Anxiety hysteria & 59 & 44.75 & 12.80 \\
\hline
\end{tabular}

\subsection{Data Analysis}

The current study was descriptive following a correlational-predictive design. To analyze the obtained data, SPSS software was used and both descriptive and inferential statistics, including stepwise regression analysis and independent t-test, were applied.

Table 2. Mean and standard deviation of dimensions of identity among the sample

\begin{tabular}{llll}
\hline Independent variable & Mean & SD & N \\
\hline Informative identity style & 29.72 & 6.66 & 240 \\
Normative identity style & 29.52 & 7.78 & 240 \\
Confused/avoidant identity style & 30.85 & 6.67 & 240 \\
Commitment identity style & 30.45 & 6.93 & 240 \\
Overall score of identity styles & 120.53 & 14.00 & 240 \\
\hline
\end{tabular}

Considering the above table, it can be observed that confused/avoidant identity style had the highest mean (30.85) and after that respectively were commitment identity style and informative identity style (with the mean of 30.45 and 29.72) and normative identity style had the lowest mean (29.52).

Table 3. Mean and standard deviation of body image

\begin{tabular}{llll}
\hline Independent variable & Mean & SD & $\mathrm{N}$ \\
\hline Body image & 136.54 & 31.37 & 240 \\
\hline
\end{tabular}

Based on the results presented in the above table, the mean of students' scores on body image was 136.54 .

Table 4. Mean and standard deviation of anxiety

\begin{tabular}{llll}
\hline Independent variable & Mean & SD & N \\
\hline Anxiety & 56.97 & 9.09 & 240 \\
\hline
\end{tabular}

With regard to the above table, the mean of students' scores on anxiety was 56.97.

\section{Results}

\subsection{First Hypothesis}

There is a significant relationship between dimensions of identity and students' anxiety. 
Table 5. Results of the analysis of Pearson correlation coefficient

\begin{tabular}{lll}
\hline \multicolumn{2}{c}{ Anxiety } \\
\hline Identity & Correlation coefficient & 0.035 \\
& Level of Significance & 0.002 \\
& $\mathrm{~N}$ & 240 \\
\hline
\end{tabular}

It can be inferred that there is a significant relationship between identity styles and anxiety in the level of $\mathrm{P}<0.05$. Therefore, with the confidence level of 0.95 , indicating that there is a significant relationship between identity style and anxiety among students.

\subsection{Second Hypothesis}

There is a significant relationship between body image and students' anxiety.

Table 6. Results of the analysis of Pearson correlation coefficient

\begin{tabular}{lll}
\hline \multicolumn{2}{c}{ Anxiety } \\
\hline Body image & Correlation coefficient & 0.84 \\
& Level of Significance & 0.01 \\
& $\mathrm{~N}$ & 240 \\
\hline
\end{tabular}

Considering the results presented in Table 6 , it can be concluded that there is a significant relationship between body image and anxiety in the level of $\mathrm{P}<0.05$. Therefore, with the confidence level of 0.95 , the research hypothesis is confirmed and the null hypothesis is rejected, indicating that there is a significant relationship between body image and anxiety among students.

Table 7. Results of bivariate regression analysis between body image and anxiety

\begin{tabular}{lllllll}
\hline \multicolumn{7}{l}{ Criterion variable of anxiety } \\
\hline Predicator variable & B & SE & Beta & T & Adjusted R & Sig \\
Body image & -0.423 & 0.018 & 0.345 & 4.60 & 0.389 & 0.00 \\
\hline
\end{tabular}

The results of Table 7 indicate that the adjusted $\mathrm{R}$ square is 0.389 , i.e. the variable of body image determines $40 \%$ of the variable of anxiety and beta and t are respectively 0.345 and 4.60 and the level of significance is $\mathrm{P}<0.01$, indicating that the predictor variable (body image) has a significant impact on the criterion variable (anxiety).

\subsection{Research Question}

Which one of identity styles has the greatest impact on anxiety?

Table 8. Results of multivariate regression analysis

\begin{tabular}{lllll}
\hline Anxiety & $\mathrm{R}$ & $\mathrm{R}^{2}$ & $\mathrm{~F}$ & $\mathrm{Sig}$ \\
\hline Dimensions of identity & 0.35 & 0.12 & 7.09 & 0.01 \\
\hline
\end{tabular}

Other results of the analysis of the multivariate regression model

\begin{tabular}{llll}
\hline & $\mathrm{B}$ & $\mathrm{T}$ & $\mathrm{Sig}$ \\
\hline Informative identity style & 0.02 & 0.15 & 0.87 \\
Normative identity style & 0.08 & 0.59 & 0.55 \\
Confused/avoidant identity style & 0.35 & 2.66 & 0.01 \\
Commitment identity style & 0.08 & 0.59 & 0.55 \\
\hline
\end{tabular}


Considering the results presented in Table 8 , it can be concluded that dimensions of identity can predict 0.12 of the variance in anxiety. When prioritizing identity styles in predicting anxiety, only confused/avoidant identity style is significant at the $\mathrm{P}<0.05$.

\section{Discussion and Conclusion}

The present study was conducted to examine the relationship of identity styles and body image with anxiety among high school students studying in the second period. With regard to the first hypothesis, the obtained results indicated that there was a significant relationship between identity styles and anxiety. Moreover, the results of regression analysis revealed that dimensions of identity style were able to predict 0.12 of the variance in anxiety. No similar studies were found in this regard; however, these results are somehow in line with the results of Berzonsky (2004) and Dollinger (1995). Moreover, the obtained results are consistent with the results of a study conducted by Ghazanfari (2003), examining the relationship between identity styles and mental health of adolescents which indicated that informative and normative identity styles were significantly and positively related to the level of mental health and there was a negative and significant relationship between confused/avoidant identity style and the level of mental health. Considering the second hypothesis, the results revealed that there was a significant relationship between body image and anxiety. The results of regression analysis indicated that the variable of body image was able to predict $3.8 \%$ of the variance in anxiety. This finding is in line with the results of Kashkouli (2012), Heidari and Khadadadi (2012), and Han and Kim (2006). Additionally, Ahmadi and Bagheri (2014) examined the mediating role of cognitive distortions in relation to body image and social anxiety among adolescents and concluded that adolescents, since they have a negative attitude towards their physical features and also due to their cognitive distortions, experience higher levels of social anxiety. Moreover, the results of khodabakhshi et al. (2014) showed that body image and anxiety were significantly related and people with low body image experienced higher levels of anxiety. These results are consistent with the results of the current study.

The results of regression analysis indicated that dimensions of identity style were able to predict 0.12 of the variance in anxiety. When prioritizing identity styles in predicting anxiety, only confused/avoidant identity style was significant at the $\mathrm{P}<0.05$. This means that with an increase in confused/avoidant identity style, anxiety will increase. The obtained results are consistent with the results of Marcia (1980). Additionally, these are in line with the results of Dollinger (1995) whom examined the relationship between confused/avoidant identity style and social adjustment among 15-18 years old adolescents and showed that using this identity style was correlated with low self-esteem and high levels of anxiety.

Moreover, the results revealed that there was a significant and negative relationship between normative identity style and anxiety in the level of $\mathrm{P}<0.05$, such that with an increase in normative identity style, anxiety will decrease. This result is somehow in line with the results of Berzonsky (2004), Dollinger (1995), and Ghazanfari (2003).

\section{References}

Ahmadi, M., \& Bagheri, M. (2014). Mediating role of cognitive distortions in the relationship of adolescents' body image with social anxiety. Journal of Behavioral Sciences, 7(4), 9-10.

Amidi, M., Ghofranipour, F. A., \& Hosseini, R. (2006). The relationship between body image dissatisfaction and BMI in female adolescents. Journal of Behavioral Sciences Research, 4(1-2), 59-65.

Baker, L., \& Gringart, E. (2009). Body image and self-esteem in older adulthood. Ageing \& Society, 29(6), 977995.

Berzonsky, M. D. (1997). Identity development, control theory, and self-regulation: An individual differences perspective. Journal of Adolescent Research, 12, 347-353.

Berzonsky, M. D. (2004). Identity Style, parental authority, and identity commitment. Journal of youth and adolescence, 33(3), 213-220.

Berzonsky, M. D. (1989). Identity style: Conceptualization and measurement. Journal of Adolescent Research, 4 , 267-281.

Borzekowski, D. L. G., \& Bayer, A. M. (2005). Body image and media use among adolescents. Adolescent Medicine Clinics, 16(2), 289-313.

Cattell, R. B. (1957). Personality and Motivation Structure and Measurement. New York: World Book.

Dehghanzadeh, M., MitraChehrzad, M., Ja'fariasl, M., Soleimani, R., \& Kazemnejad, L. (2011). The level of satisfaction with body image in female adolescents in high schools of Rasht. Nursing and Midwifery, 21(66), 
$7-12$.

Dollinger, S. M. (1995). Identity styles and five-factor model of personality. Journal of Research in Personality, $29,475-479$.

Erikson, E. H. (1959). Identity and the life cycle. New York: International Universities Press.

Fisher, S. (1970). Body experience in fantasy and behavior. New York: Appleton Century-Crofts.

Ganji, H. (2001). Personality assessment. Tehran: Savalan Publication.

Ghazanfari, A. (2003). Examining identity styles of students with their mental health. Quarterly of Education and Psychology Studies, 4(1), 227-244.

Ghazzanfari, A. (2003). Validation and standardization of Identity Style Inventory (2nd ed.). Mashhad: Ferdowsi University of Psychology and Education Studies Publication.

Gleeson, K. (2006). Constructing body Image. Journal of Health Psychology, 11(7), 79-90.

Gorousi, B., Razavi Ne'matullahi, V., \& Etminan Rafsanjani, A. (2013). Relationship of depression and self-esteem with body image in pregnant women. Journal of Health and Development, 2(2), 117-127.

Han, S. S., \& Kim, K.M. (2006). Influencing factors on self-esteem in adolescents. Ttaehan Kanho Hakhoe Chi, $36(1), 37-44$.

Heidari, A., \& Khodadadi, A. (2012). Comparing social anxiety and concerns about body image among male and female students. Journal of New Findings in Psychology, 7(22), 83-97.

Hosseini Tabatabaee, F. (1998). Relationship between Identity Statuses and coping with crisis in adolescents and young adults in Mashhad. MA Thesis, Department of Psychology, Al-Zahra University.

Kashkouli, A. R. (2012). Investigating the relationship of body image and obsession with social anxiety and changes in these variables in women participated in weight loss programs. MA Thesis of Psychology, Ardabil University.

Khodabakhshi Koolaee, A., Rastak, H., Mansour, L., \& Rashidkhani, B. (2014). The relationship of dietary patterns with body image and anxiety in adolescents. Journal of Psychiatric Nursing, 2(4), 12-25.

Marcia, J, E. (1980). Identity and adolescence, In J.E. Adelson (Ed.), Hand book for Adolescent psychology. New York: Wiley.

Pahlavanzdeh, S., Maghsoudi, J., Ghazavi, Z., \& Habibpour, Z. (2005). Satisfaction with body image and BMI in adolescents. Journal of Behavioral Sciences Research, 3(1), 39-44.

Rahdar, Z. (2013). Obsessive-compulsive symptoms related to body image and self-concept of high school students in the city of Zahedan. MA thesis, General Psychology, University of Sistan and Baluchestan.

Webster, J., \& Tiggemann, M. (2003). The relationship between women's body satisfaction and self-image across the life span: the role of cognitive control. Journal of Genetic Psychology, 164(2), 241-253.

Yazdanjo, Q. (2000). Examining the relationship between body and the level of adaptation of female high school students in Mashhad. MA Thesis of counseling, School of Management and Planning, Ministry of Education.

\section{Copyrights}

Copyright for this article is retained by the author(s), with first publication rights granted to the journal.

This is an open-access article distributed under the terms and conditions of the Creative Commons Attribution license (http://creativecommons.org/licenses/by/3.0/). 